\title{
Membangun Kepuasan Mahasiswa Pengguna Laboratorium Komputer
}

\author{
Mumuh Mulyana ${ }^{1}$, Marwan Effendy² ${ }^{2}$ Lukman Hidayat $^{3}$
}

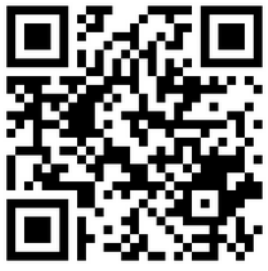

\begin{abstract}
Abstrak
Penelitian ini bertujuan untuk menganalisis faktor-faktor kualitas pelayanan yang membentuk kepuasan mahasiswa dalam penggunaan sarana Laboratorium Komputer. Penelitian dilakukan pada Laboratorium Komputer STIE Kesatuan dengan jumlah responden sebanyak 100 orang mahasiswa. Data dianalisis menggunakan pendekatan Structural Equation Model. Hasil penelitian menunjukkan variabel Bukti Fisik, Empati, Jaminan, Kehandalan dan Ketanggapan mampu menjelaskan variability konstruk Kualitas Pelayanan dengan kuat sebesar $69,53 \%$. Kelima unsur Kualitas Pelayanan memiliki hubungan positif dan signifikan terhadap Kepuasan Mahasiswa
\end{abstract}

Kata Kunci: kualitas pelayanan, laboratorium komputer, kepuasan mahasiswa

\section{Abstract}

The purpose of this research is to analyze the service quality factors that influence on student satisfaction when they use Computer Laboratory. The study was conducted at the STIE Kesatuan Laboratory of Computer with 100 students as the respondents. Data were analyzed using Structural Equation Model approach. Results showed variable Physical Evidence, Empathy, Security, Reliability and Responsiveness able to explain the variability construct of Service Quality strongly by 69.53\%. The fifth element of service quality has a positive and significant relationship to the Student Satisfaction

Keywords: service quality,laboratory of computer, student satisfaction
1. Program Studi

Manajemen Pemasaran, STIE Kesatuan, Jl. Ranggagading No. 1 Bogor, 16123 Jawa Barat Indonesia

EMail

mul.mubarak@gmail.com

2. Program Studi Akuntansi, STIE Kesatuan, Jl. Ranggagading No. 1 Bogor, 16123 Jawa Barat Indonesia

3. Program Studi Manajemen, STIE Kesatuan, Jl.

Ranggagading No. 1

Bogor, 16123 Jawa Barat Indonesia

Submitted Desember 2017

Accepted : Desember 2017

\section{Pendahuluan}

Proses meningkatkan sumber daya manusia yang memiliki intelektual dan unggul, mampu bersaing dalam bidangnya, tidak terlepas dari peranan Perguruan Tinggi sebagai institusi pendidikan. Perguruan Tinggi bertugas menghasilkan lulusan-Iulusan yang berkualitas. Proses belajar dan mengajar saja tidak cukup tetapi perlu didukung dengan fasilitas-fasilitas penunjang lainnya seperti Laboratorium Komputer, sebagai salah satu sarana pelayanan.

Secara umum, Laboratorium Komputer adalah pelayanan. Kepuasan pelanggan (mahasiswa) menjadi salah satu tujuan pelayanan suatu Laboratorium Komputer. Untuk mencapai tujuan pelayanan yang berkualitas, Laboratorium Komputer dituntut untuk memenuhi kebutuhan masyarakat penggunanya. Tidak saja terpenuhinya fasilitasfasilitas fisik tetapi perlu juga diperhatikan sumber dan akses informasi, kualitas
JAS-PT

JURNAL ANALISIS SISTEM PENDIDIKAN TINGG

ISSN $2580-5339$

Volume 1

Nomor 2

DESEMBER 2017

Hal $93-101$

FORUM DOSEN INDONESIA 
pelayanan, dan teknologi yang dapat membantu proses pelayanan sehingga tercapainya kepuasan pemakai.

Laboratorium Komputer STIE Kesatuan merupakan salah satu unit pelaksana teknis di lingkungan STIE Kesatuan Bogor dengan fasilitas yang relatif memadai. Namun demikian, masih diakui bahwa masih terdapat keluhan yang disampaikan oleh para mahasiswa. Tentu hal ini tidak boleh dibiarkan begitu saja. Diperlukan perhatian dan penanganan yang efektif agar kepuasan mahasiswa dalam menggunakan sarana Laboratorium Komputer dapat diciptakan.

Untuk mengetahui faktor-faktor yang kualitas pelayanan yang membentuk kepuasan mahasiswa dalam penggunaan sarana Laboratorium Komputer, peneliti mencoba melihat pengaruh tersebut berdasarkan pada lima dimensi, yaitu: Bukti fisik, adalah aspek-aspek nyata yang bisa dilihat dan diraba, termasuk sumber daya manusia. Kehandalan, adalah aspek-aspek kehandalan sistem pelayanan yang diberikan oleh Laboratorium Komputer, apakah jasa yang diberikan sesuai dengan standar-standar umum atau kemampuan mewujudkan jasa sesuai dengan yang telah dijanjikan secara cepat. Ketanggapan, adalah keinginan untuk membantu mahasiswa dan menyediakan jasa yang dibutuhkan atau kecepat-tanggapan dari petugas labotraotirum dalam memberikan jasa serta dapat menangkap aspirasi-aspirasi yang muncul dari mahasiswa. Jaminan, adalah bahwa jasa yang diberikan memberikan jaminan kenyamanan, kemampuan sumber daya dalam memberikan pelayanan yang sesuai dengan standar. Empati, adalah kemudahan dalam mendapatkan pelayanan, keramahan, komunikasi, dan kemampuan memahami kebutuhan mahasiswa.

Berdasarkan latar belakang di atas dirumuskan masalah sebagai berikut: (a) Bagaimana model struktural kualitas pelayanan Laboratorium Komputer STIE Kesatuan Bogor? (b) Bagaimana pengaruh bukti fisik, kehandalan, ketanggapan, jaminan, dan empati Laboratorium Komputer terhadap kepuasan mahasiswa STIE Kesatuan Bogor?

\section{Tinjauan Pustaka}

Gronroos (dalam Ratminto dan Winarsih 2005) "Pelayanan adalah suatu aktivitas atau serangkaian aktivitas yang bersifat tidak kasat mata (tidak dapat diraba) yang terjadi sebagai akibat adanya interaksi antara konsumen dengan karyawan atau hal-hal lain yang disediakan oleh perusahaan pemberi pelayanan yang dimaksudkan untuk memecahkan permasalahan konsumen/pelanggan".

Kualitas adalah merupakan variabel yang sangat penting dalam dunia bisnis, termasuk bisnis jasa. Di dalam penelitian, kualitas harus dikonseptualisasikan dengan suatu definisi operasional, sehingga dapat diukur dengan suatu instrumen. Menurut Ellitan (2001); Dimensi kualitas pelayanan pada industri jasa yaitu (1) Fungsi, kinerja primer yang dituntut dari suatu jasa (2) Karakteristik, kinerja yang diharapkan (3) Kesesuaian, kepuasan didasarkan pada pemenuhan persyaratan yang ditetapkan (4). Kehandalan, kepercayaan terhadap jasa dalam kaitan waktu (5) Kemampuan pelayanan, kemampuan melakuakan perbaikan apabila terjadi kekeliruan (6) Estetika, pengalaman pelanggan yang berkaitan dengan perasaan dan panca indra".

JAS-PT

JURNAL ANALISIS SISTEM PENDIDIKAN TINGGI ISSN $2580-5339$ Volume 1 Nomor 2 DESEMBER 2017 Hal $93-101$

FORUM DOSEN INDONESIA
Pada penelitian lanjutnya oleh Parasuraman, et al. (1988) terdapat 5 (lima) dimensi untuk menentukan kualitas pelayanan, yaitu :

a. Tangibles, meliputi fasilitas fisik, peralatan dan perlengkapan, serta penampilan personil.

b. Reliability, meliputi aspek-aspek kehandalan sistem pelayanan yang diberikan oleh perpustakaan 
c. Responsiveness, meliputi ketanggapan untuk membantu mahasiswa dan menyediakan jasa dan pelayanan yang dibutuhkan

d. Assurance, jasa yang diberikan memberikan jaminan keamanan, kompetensi sumber daya dalam pelayanan

e. Empathy, kemudahan dalam mendapatkan pelayanan, keramhan, komunikasi, dan memahami kebutuhan konsumen

\section{Metode Penelitian}

Penelitian ini dilaksanakan di Laboratorium Komputer STIE Kesatuan di Jalan Ranggagading No. 1 Bogor, selama tiga bulan mulai Maret 2017 sampai dengan bulan Mei 2017. Laboratorium Komputer STIE Kesatuan merupakan salah satu unit pelaksana teknis dari institusi STIE Kesatuan yang menjalankan fungsi layanan Laboratorium Komputer kepada para sivitas akademika STIE Kesatuan dan pihak eksternal. Jenis penelitian adalah penelitian deskriptif kuantitatif.

Populasi dari penelitian ini adalah mahasiswa STIE Kesatuan, yang terdaftar pada BAAK STIE Kesatuan sebanyak 1.772 orang. Penarikan sample penelitian ini menggunakan metode rumus Slovin, sebanyak 100 orang. Sampel penelitian ini adalah mahasiswa yang sedang berkunjung ke Laboratorium Komputer pada saat peneliti melakukan penelitian. Model Penelitian ini tergambar pada Gambar 1

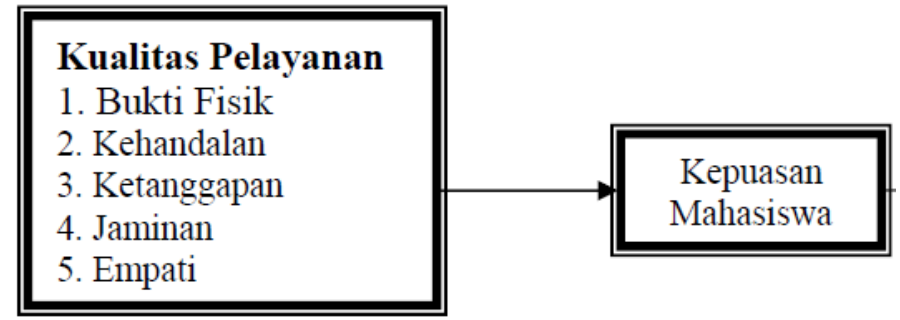

\section{Gambar 1. Kerangka Pemikiran}

Berdasarkan tujuan penelitian, perumusan masalah dan kerangka pemikiran, peneliti mengajukan hipotesis sebagai berikut :

1. Bukti fisik berpengaruh positif terhadap kepuasan mahasiswa dalam menggunakan Laboratorium Komputer STIE Kesatuan Bogor

2. Kehandalan berpengaruh positif terhadap kepuasan mahasiswa dalam menggunakan Laboratorium Komputer STIE Kesatuan Bogor

3. Ketanggapan berpengaruh positif terhadap kepuasan mahasiswa dalam menggunakan Laboratorium Komputer STIE Kesatuan Bogor

4. Jaminan berpengaruh positif terhadap kepuasan mahasiswa dalam menggunakan Laboratorium Komputer STIE Kesatuan Bogor

5. Empati berpengaruh positif terhadap kepuasan mahasiswa dalam menggunakan Laboratorium Komputer STIE Kesatuan Bogor

Untuk menganalisis data digunakan pendekatan Partial Least Square (PLS). Software SMARTPLS versi $2.0 \mathrm{M}$ digunakan dalam mengolah data pada penelitian ini.

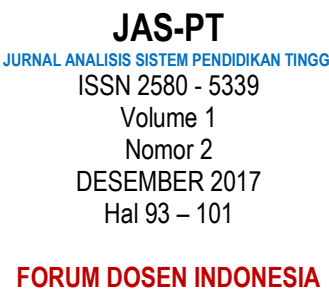

SN $2580-5339$

Volume 1

Hal $93-101$

FORUM DOSEN INDONESIA 
Hasil Penelitian dan Pembahasan

\section{Karakteristik Responden}

Sebaran Responden berdasarkan karakteristik dapat terlihat pada Tabel 1.

Tabel 1 Distribusi Frekuensi Responden Berdasarkan Karakteristik

\begin{tabular}{lccc}
\hline \multicolumn{1}{c}{ Karakteristik } & Frekuensi & Prosentase & Jumlah \\
\hline Jenis Kelamin Responden & & & \\
Laki-laki & 26 & 26,0 & 100 \\
Wanita & 74 & 74,0 & \\
Usia Responden & 9 & 9,0 & \\
19 Tahun & 36 & 36,0 & \\
20 Tahun & 23 & 23,0 & 100 \\
21 Tahun & 20 & 20,0 & \\
22 Tahun & 7 & 7,0 & \\
23 Tahun & 5 & 5,0 & \\
> 23 Tahun & & & \\
Program Studi Responden & 20 & 20,0 & \\
Manajemen S1 & 20 & 20,0 & \\
Akuntansi S1 & 20 & 20,0 & \\
Pemasaran D3 & 20 & 20,0 & \\
Keuangan dan Perbankan D3 & 20 & 20,0 & \\
Akuntansi D3 & & & \\
Kelas Perkuliahan Responden & 72 & 72,0 & \\
Kelas Reguler Pagi & 8 & 8,0 & \\
Kelas Reguler Sore & 20 & 20,0 & \\
Kelas Karyawan & & & \\
\hline
\end{tabular}

Sumber : Hasil Pengolahan Data Primer, 2017

\section{Analisis Model Pengukuran Pelayanan Laboratorium Komputer}

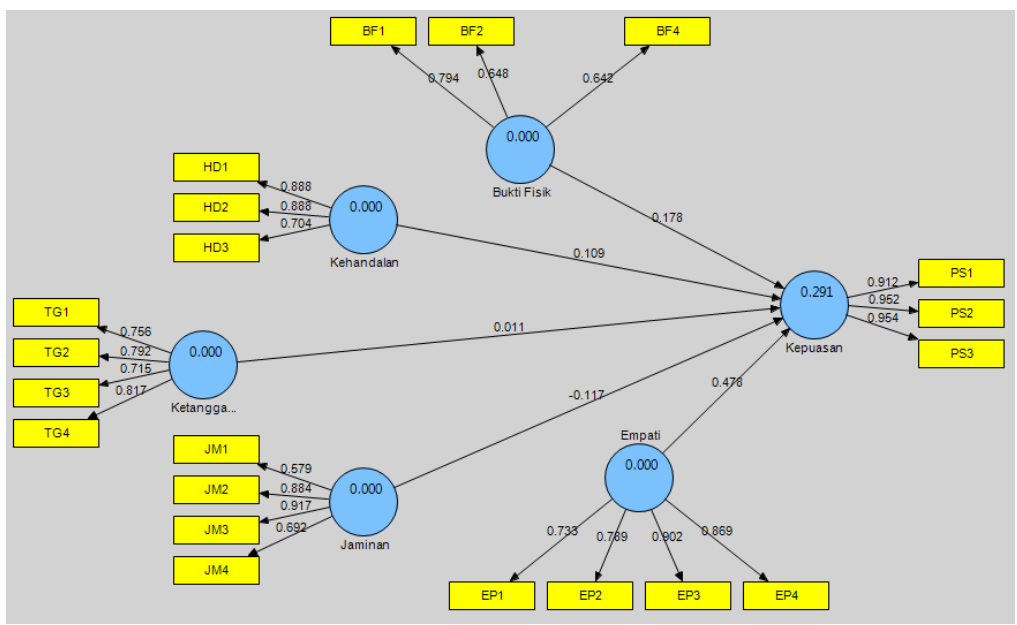

Gambar 2. Model Kualitas Pelayanan Laboratorium Komputer STIE Kesatuan

Model awal dibentuk setelah dilakukan terlebih dahulu analisis terhadap data-data empiris dan teori tentang Kualitas Pelayanan dapat dilihat pada gambar 2. Dalam model tersebut, Kualitas Pelayanan Laboratorium Komputer dibentuk oleh variabel

JAS-PT

JURNAL ANAUSIS SISTEM PENDIDIKAN TINGG

ISSN 2580 - 5339

Volume 1

Nomor 2

DESEMBER 2017

Hal $93-101$

FORUM DOSEN INDONESIA
Bukti Fisik, Kehandalan, Ketanggapan, Jaminan dan Empati. Pelayanan Laboratorium Komputer mempengaruhi Kepuasan Mahasiswa sebagai Anggota Laboratorium Komputer. Model tersebut telah mengalami teknik trimming yang menyebabkan dikeluarkannya dua indikator yaitu $\mathrm{BF} 3(0,467)$ dan $\operatorname{HD} 4(0,220)$ yang memiliki nilai loading factor kurang dari 0,500 . Nilai loading factor merupakan korelasi antara indikator tersebut dengan konstraknya. Semakin tinggi korelasinya, menunjukkan 
tingkat validitas yang lebih baik. Uji signifikansi loading factor ditetapkan dengan memperhatikan nilai t-statistic yang harus lebih dari 2,000 (Lihat Tabel 2).

Tabel 2 Outer Loading

\begin{tabular}{lcc}
\hline \multicolumn{1}{c}{ Indicator/Construct } & Original Sample $(0)$ & T Statistics $(|\mathrm{O} / \mathrm{STERR}|)$ \\
\hline BF1 <- Bukti Fisik & 0.793746 & 4.313863 \\
BF2 <- Bukti Fisik & 0.647525 & 2.967928 \\
BF4 <- Bukti Fisik & 0.641815 & 3.024296 \\
EP1 <- Empati & 0.732524 & 2.848233 \\
EP2 <- Empati & 0.788609 & 3.225205 \\
EP3 <- Empati & 0.902033 & 5.618451 \\
EP4 <- Empati & 0.869028 & 3.981158 \\
HD1 <- Kehandalan & 0.888278 & 6.884206 \\
HD2 <- Kehandalan & 0.887922 & 4.731813 \\
HD3 <- Kehandalan & 0.703949 & 2.730252 \\
JM1 <- Jaminan & 0.578953 & 2.305410 \\
JM2 <- Jaminan & 0.884052 & 2.873216 \\
JM3 <- Jaminan & 0.916873 & 2.611564 \\
JM4 <- Jaminan & 0.692482 & 2.583846 \\
PS1 <- Kepuasan & 0.911576 & 31.694632 \\
PS2 <- Kepuasan & 0.952026 & 60.422661 \\
PS3 <- Kepuasan & 0.953658 & 58.076978 \\
TG1 <- Ketanggapan & 0.756415 & 2.365985 \\
TG2 <- Ketanggapan & 0.792262 & 2.535920 \\
TG3 <- Ketanggapan & 0.715101 & 2.943690 \\
TG4 <- Ketanggapan & 0.816716 & 2.984208 \\
\hline
\end{tabular}

Sumber: Hasil Pengolahan Data Primer, 2017

Analisis selanjutnya dari convergent validity adalah reliabilitas konstruk dengan melihat output composite reliability atau cronbach's alpha. Kriteria dikatakan reliable adalah nilai composite reliability atau cronbach's alpha lebih dari 0,70 . Berdasarkan Tabel 3 seluruh konstruk dapat dinyatakan reliable.

Tabel 3 Nilai AVE, Communality, Composite Reliability dan Cronbach Alpha Variabel-variabel Penelitian

\begin{tabular}{lcccc}
\hline \multicolumn{1}{c}{ Construct } & AVE & Composite Reliability & Communality & Cronbachs Alpha \\
\hline Bukti Fisik & 0.587083 & 0.738219 & 0.587083 & 0.843615 \\
Empati & 0.681842 & 0.894921 & 0.681841 & 0.859732 \\
Jaminan & 0.609231 & 0.857934 & 0.609230 & 0.818012 \\
Kehandalan & 0.690996 & 0.869032 & 0.690996 & 0.785870 \\
KEPUASAN & 0.882262 & 0.957394 & 0.882262 & 0.933093 \\
Ketanggapan & 0.594559 & 0.854043 & 0.594557 & 0.788725 \\
\hline
\end{tabular}

Sumber: Hasil Pengolahan Data Primer, 2017

Pemeriksaan terakhir dari convergent validity adalah melihat output AVE. konstrak memiliki covergent validity yang baik adalah apabila memiliki nilai AVE lebih dari 0,50. Berdasarkan tabel, semua nilai AVE konstrak Bukti Fisik, Empati, Jaminan, Kehandalan, Ketanggapan, dan Kepuasan, memiliki nilai AVE di atas 0,50.

Evaluasi discriminant validity dilakukan dalam dua tahap, yaitu melihat nilai cross loading dan membandingkan antara nilai kuadrat korelasi antara konstrak dengan nilai AVE atau korelasi antara konstrak dengan akar AVE. Berdasarkan hasil tabel cross loading di atas, setiap indikator berkorelasi lebih tinggi dengan konstraknya masingmasing dibandingkan dengan konsntrak lainnya, sehingga dapat dinyatakan memiliki discriminant validity yang baik.

Pemeriksaan selanjutnya adalah membandingkan antara korelasi variabel laten dengan akar AVE konstrak. Secara keseluruhan dalam tabel di atas, setiap konstrak memiliki nilai akar AVE yang lebih besar dari korelasi antar konstrak. Hal ini menunjukkan bahwa seluruh konstrak memiliki validity yang baik.

\footnotetext{
JAS-PT

JURNAL ANALISIS SISTEM PENDIDIKAN TINGGI ISSN $2580-5339$ Volume 1 Nomor 2 DESEMBER 2017 Hal $93-101$

FORUM DOSEN INDONESIA
} 
Tabel 4 Cross Loading

\begin{tabular}{|c|c|c|c|c|c|c|}
\hline Indikator & Bukti Fisik & Empati & Jaminan & Kehandalan & Kepuasan & Ketanggapan \\
\hline BF1 & 0.793746 & 0.171786 & 0.139737 & 0.055357 & 0.266874 & 0.203866 \\
\hline BF2 & 0.647525 & 0.172807 & 0.001332 & 0.296007 & 0.185684 & 0.080878 \\
\hline BF4 & 0.641815 & 0.126620 & 0.065059 & 0.332581 & 0.173468 & 0.036104 \\
\hline EP1 & 0.097233 & 0.732524 & 0.614681 & 0.188564 & 0.228486 & 0.259141 \\
\hline EP2 & 0.114495 & 0.788609 & 0.493184 & 0.150072 & 0.198783 & 0.315345 \\
\hline EP3 & 0.135127 & 0.902033 & 0.439327 & 0.189050 & 0.389704 & 0.341566 \\
\hline EP4 & 0.293011 & 0.869028 & 0.446914 & 0.217973 & 0.561507 & 0.218464 \\
\hline HD1 & 0.251095 & 0.199468 & 0.159084 & 0.888278 & 0.272844 & 0.242836 \\
\hline HD2 & 0.246681 & 0.181675 & 0.102254 & 0.887922 & 0.187662 & 0.224039 \\
\hline HD3 & 0.222974 & 0.208199 & 0.183783 & 0.703949 & 0.132486 & 0.286393 \\
\hline JM1 & 0.206510 & 0.376026 & 0.578953 & 0.156644 & -0.006742 & 0.450328 \\
\hline $\mathrm{JM} 2$ & 0.193910 & 0.475700 & 0.884052 & 0.150460 & 0.171782 & 0.396677 \\
\hline JM3 & 0.032098 & 0.538525 & 0.916873 & 0.161730 & 0.193706 & 0.295841 \\
\hline JM4 & -0.004407 & 0.440390 & 0.692482 & 0.128298 & 0.028341 & 0.188653 \\
\hline PS1 & 0.293354 & 0.481973 & 0.235100 & 0.212307 & 0.911576 & 0.166078 \\
\hline PS2 & 0.267696 & 0.466621 & 0.173315 & 0.279449 & 0.952026 & 0.235869 \\
\hline PS3 & 0.303089 & 0.398693 & 0.141307 & 0.219198 & 0.953658 & 0.112357 \\
\hline TG1 & 0.041500 & 0.127969 & 0.247201 & 0.240988 & 0.049104 & 0.756415 \\
\hline TG2 & 0.117362 & 0.232182 & 0.301649 & 0.335589 & 0.148065 & 0.792262 \\
\hline TG3 & 0.168803 & 0.239006 & 0.317511 & 0.143785 & 0.110431 & 0.715101 \\
\hline TG4 & 0.148990 & 0.311701 & 0.272957 & 0.187270 & 0.186723 & 0.816716 \\
\hline
\end{tabular}

Sumber: Hasil Pengolahan Data Primer, 2017

Tabel 5 Korelasi Variabel Laten

\begin{tabular}{lrlllll}
\hline \multicolumn{1}{c}{ Konstrak } & Bukti Fisik & Empati & Jaminan & Kehandalan & Kepuasan & Ketanggapan \\
\hline Bukti Fisik & 1.000000 & & & & & \\
Empati & 0.225298 & 1.000000 & & & & \\
Jaminan & 0.110115 & 0.567739 & 1.000000 & & & \\
Kehandalan & 0.287391 & 0.231159 & 0.173105 & 1.000000 & & \\
Kepuasan & 0.306251 & 0.480291 & 0.196644 & 0.253285 & 1.000000 & \\
Ketanggapan & 0.170698 & 0.324568 & 0.370111 & 0.291173 & 0.184999 & 1.000000 \\
\hline
\end{tabular}

Sumber: Hasil Pengolahan Data Primer, 2017

Tabel 6 AVE dan Akar AVE Variabel Penelitian Pelayanan Laboratorium Komputer

\begin{tabular}{|c|c|c|}
\hline Construct & AVE & Akar AVE \\
\hline Bukti Fisik & 0.587083 & 0.766213 \\
\hline Empati & 0.681842 & 0.825737 \\
\hline Jaminan & 0.609231 & 0.780533 \\
\hline Kehandalan & 0.690996 & 0.831262 \\
\hline KEPUASAN & 0.882262 & 0.939288 \\
\hline Ketanggapan & 0.594559 & 0.771077 \\
\hline
\end{tabular}

Sumber: Hasil Pengolahan Data Primer, 2017

\section{Analisis Model Struktural Kualitas Pelayanan Laboratorium Komputer।}

Setelah evaluasi model pengukuran terpenuhi, maka selanjutnya adalah evaluasi terhadap model struktural. Pada tahap pengujian inner model, diperoleh $\mathrm{R}^{2}$ sebesar 0,695315 untuk konstruk Kepuasan yang dipengaruhi oleh konstruk Bukti Fisik, Empati, Jaminan, Kehandalan dan Ketanggapan. Hal tersebut menunjukkan bahwa kelima variabel mampu menjelaskan variability konstruk Kepuasan Mahasiswa sebesar

JAS-PT

JURNAL ANALISIS SISTEM PENDIDIKAN TINGG ISSN $2580-5339$

Volume 1

Nomor 2

DESEMBER 2017

Hal $93-101$

FORUM DOSEN INDONESIA
$69,53 \%$ dan sisanya dijelaskan oleh variabel lain.

Chin (1998) mengelompokkan $R^{2}$ ke dalam tiga kategori yaitu Substansial $(0,67)$, Moderat $(0,33)$ dan Lemah $(0,19)$. Dengan merujuk Chin (1998), maka dapat dinyatakan bahwa variabel Kualitas Pelayanan memiliki $\mathrm{R}^{2}$ yang berada pada level Substansial yang mampu menjelaskan konstruk dengan kuat. 


\begin{tabular}{ll}
\hline \multicolumn{1}{c}{ Konstrak } & R Square \\
\hline Bukti Fisik & \\
Empati & \\
Jaminan & \\
KEPUASAN & 0,695315 \\
Kehandalan & \\
Ketanggapan & \\
\hline
\end{tabular}

Sumber: Hasil Pengolahan Data Primer, 2017

Tabel 8 menunjukkan nilai koefisien parameter untuk konstruk Bukti Fisik terhadap Kepuasan adalah sebesar 0,178363 dan nilai t-statistik sebesar 1,977008 (t-statistic < 1.96). Hal ini menunjukkan bahwa Bukti Fisik memiliki hubungan positif terhadap Kepuasan Mahasiswa secara signifikan. Dengan demikian, Laboratorium Komputer STIE Kesatuan dianggap perlu terus melakukan pengembangan dalam hal Bukti Fisik.

Tabel 8 Nilai Hasil bootstrap Koefisien Jalur Kualitas Pelayanan terhadap Kepuasan Mahasiswa Anggota Laboratorium Komputer STIE Kesatuan

\begin{tabular}{lccccc}
\hline \multicolumn{1}{c}{ Variabel } & $\begin{array}{c}\text { Original } \\
\text { Sample (O) }\end{array}$ & $\begin{array}{c}\text { Sample } \\
\text { Mean (M) }\end{array}$ & $\begin{array}{c}\text { Standard Deviation } \\
(\text { STDEV })\end{array}$ & $\begin{array}{c}\text { Standard Error } \\
(\text { STERR })\end{array}$ & $\begin{array}{c}\text { T Statistics } \\
(\text { (O/STERR|) }\end{array}$ \\
\hline Bukti Fisik -> Kepuasan & 0.178363 & 0.196440 & 0.097095 & 0.097095 & 1.977008 \\
Empati -> Kepuasan & 0.477963 & 0.429646 & 0.230216 & 0.230216 & 2.076148 \\
Jaminan -> Kepuasan & 0.117304 & 0.161262 & 0.186660 & 0.186660 & 2.628436 \\
Kehandalan -> Kepuasan & 0.108577 & 0.122476 & 0.102551 & 0.102551 & 2.658765 \\
Ketanggapan -> Kepuasan & 0.011222 & 0.062352 & 0.121575 & 0.121575 & 1.992310 \\
\hline
\end{tabular}

Sumber: Hasil Pengolahan Data Primer, 2017

Nilai koefisien parameter untuk konstruk Empati terhadap Kepuasan adalah sebesar 0,477963 dan nilai t-statistik sebesar 2,076148. Hal ini menunjukkan bahwa Empati memiliki hubungan positif dan berpengaruh signifikan terhadap Kepuasan Mahasiswa. Empati dari para Petugas Laboratorium Komputer akan sangat menentukan tingkat kepuasan mahasiswa dalam proses menerima layanan Laboratorium Komputer. Semakin meningkatnya sikap keramahan, sikap kesediaan untuk membantu, serta sikap perhatian dari petugas Laboratorium Komputer, akan semakin meningkatkan kepuasan mahasiswa dalam menggunakan layanan Laboratorium Komputer.

Nilai koefisien parameter untuk konstruk Jaminan terhadap Kepuasan Mahasiswa adalah sebesar 0.117304 dan nilai t-statistik sebesar 2,628436. Hal ini mengandung makna bahwa Jaminan, yang terdiri dari kompetensi, kesabaran serta kemampuan petugas Laboratorium Komputer dalam memberikan layanan kepada mahasiswa sehingga merasa nyaman, memiliki hubungan positif dan berpengaruh signifikan terhadap Kepuasan Mahasiswa. Jika Petugas Laboratorium Komputer tidak kompeten, tidak sabar dan tidak mampu memberikan rasa nyaman kepada mahasiswa saat memberikan layanan Laboratorium Komputer.

Konstruk Kehandalan terhadap Kepuasan Mahasiswa memiliki nilai koefisien parameter sebesar 0,108577 dan nilai t-statistik sebesar 2,658765. Hal ini mengandung makna bahwa Kehandalan memiliki hubungan positif dan berpengaruh signifikan terhadap Kepuasan Mahasiswa. Unsur-unsur Kehandalan seperti kesesuaian, ketepatan waktu, perhatian serius, keakurasian administrasi dan kehandalan penyampaian jasa layanan dari Petugas Laboratorium Komputer berpotensi untuk meningkatkan Kepuasan Mahasiswa.

Tabel 8 menunjukkan bahwa nilai koefisien parameter untuk konstruk Ketanggapan terhadap Kepuasan adalah sebesar 0,011222 dan nilai t-statistik sebesar 1.992310. Hal ini menunjukkan bahwa Ketanggapan memiliki hubungan positif dan berpengaruh signifikan terhadap Kepuasan Mahasiswa. Ketanggapan dari para Petugas Laboratorium Komputer akan sangat menentukan tingkat kepuasan mahasiswa dalam

\footnotetext{
JAS-PT

JURNAL ANALISIS SISTEM PENDIDIKAN TINGG

ISSN $2580-5339$

Volume 1

Nomor 2

DESEMBER 2017

Hal $93-101$

FORUM DOSEN INDONESIA
} 
proses menerima layanan Laboratorium Komputer. Kepuasan Mahasiswa dapat ditingkatkan dengan meningkatkan sikap tanggap petugas Laboratorium Komputer dalam merespon keluhan, kesediaan membantu kesulitan dan keluangan waktu untuk menanggapi permintaan mahasiswa.

Dari uraian di atas dapat dinyatakan bahwa Kepuasan Mahasiswa Anggota Laboratorium Komputer STIE Kesatuan dapat ditingkatkan dengan melakukan peningkatan pada aspek Kualitas Pelayanan. Jika kelima aspek tersebut menurun maka akan menyebabkan penurunan tingkat kepuasan mahasiswa dalam menggunakan layanan Laboratorium Komputer.

\section{Kesimpulan dan Saran}

Beberapa kesimpulan dan rekomendasi dari Penelitian ini adalah sebagai berikut :

1. Penelitian dilakukan di Laboratorium Komputer STIE Kesatuan Bogor dengan Populasi penelitian adalah Mahasiswa STIE Kesatuan Bogor. Responden Mayoritas dalam penelitian ini adalah responden berjenis kelamin Wanita, Usia 20 tahun, berasal dari program studi Manajemen S1, mahasiswa kelas Perkuliahan Reguler Pagi.

2. Model awal Pelayanan Laboratorium Komputer dibentuk oleh variabel Bukti Fisik, Kehandalan, Ketanggapan, Jaminan dan Empati kemudian Pelayanan Laboratorium Komputer mempengaruhi Kepuasan Mahasiswa sebagai Anggota Laboratorium Komputer dan Kepuasan Mahasiswa mempengaruhi Loyalitas Mahasiswa. Variabel Bukti Fisik, Empati, Jaminan, Kehandalan dan Ketanggapan mampu menjelaskan variability konstruk Kualitas Pelayanan dengan kuat sebesar $69,53 \%$ dan sisanya dijelaskan oleh variabel lain.

3. Kelima unsur Kualitas Pelayanan memiliki hubungan positif dan signifikan terhadap Kepuasan Mahasiswa. Dengan demikian menjadi penting bagi manajemen untuk terus melakukan upaya peningkatan kualitas pelayanan Laboratorium Komputer untuk menciptakan Kepuasan Mahasiswa dalam penggunaan fasilitasnya.

4. Menjadi penting bagi pimpinan untuk melakukan pembinaan dan pengembangan keterampilan dan keahlian bagi para pustakawan dan staf Laboratorium Komputer untuk menghadirkan dan menciptakan layanan prima bagi anggota Laboratorium Komputer sehingga mampu meningkatkan kepuasan para mahasiswa yang pada akhirnya berpengaruh terhadap peningkatan prestasi akademis para mahasiswa.

5. Penelitian yang dimasudkan untuk melakukan pengukuran kepuasan dan loyalitas pengguna laboratorium perlu dilakukan secara berkala dan terprogram. Sehingga proses monitoring dan evaluasi layanan Laboratorium Komputer dapat dilakukan secara berkelanjutan.

\section{Daftar Pustaka}

JAS-PT

ISSN $2580-5339$

Volume 1

Nomor 2

DESEMBER 2017

Hal $93-101$

FORUM DOSEN INDONESIA
Budiharjo, Utari. 1993. "Informasi, Kebutuhan Pemakai dan Jasa Informasi". Majalah IPI $4(3): 105-113$.

Ellitan, Lenna. 2001. "Strategi Mendongkrak Kualitas Pelayanan". Jurnal Ekonomi Sekolah Tinggi Ilmu Ekonomi Indonesia 15/Th. X.

Gefen, David. 2002. "Customer Loyalty in E-Commerce." Journal of The Association for Information Systems 3 
Irawan, Handi. 2003. 10 Prinsip Kepuasan Pelanggan. Elex Media Komputindo, Jakarta.

Kotler, Philip and Alan R. Andreason. 1995. Strategi Pemasaran untuk Organisasi Nirlaba. Edisi Ketiga. Penerjemah Ova Emi Emiliam. Penyunting Mubasyir Hasan Basri. Gadjah Mada University, Yogyakarta.

Lupiyoadi, Rambat. 2001. Manajemen Pemasaran Jasa : Teori dan Praktek. Salemba Empat, Jakarta.

Mardalis, Ahmad. 2005. "Meraih Loyalitas Pelanggan". Jurnal Manajemen dan Bisnis 9 No. 2 (Tahun 2005) : 111-119.

Maulana, Amalia E. 2005. "Membentuk Loyalitas Konsumen.". Majalah Swa (2007).

Moenir, H.A.S. 2004. Manajemen Pelayanan Umum di Indonesia. Bumi Aksara, Jakarta.

Nurendah, Y. and Mulyana, M., 2013. Analisis Pengaruh Kualitas Pelayanan Perpustakaan Terhadap Kepuasan dan Hubungannya dengan Loyalitas Mahasiswa. Jurnal IImiah Manajemen Kesatuan, 1(1), pp.91-105.

Parasuraman, A. Zeithaml V.A. and Berry L.L. 1988. "A Multiple Item Scale for Measuring Consumer Perception of Service Quality". Journal of Retailling Vol. 64, spring: $12-14$.

Puspitasari, R. and Mubarak, M.M., 2012. Perilaku Pembelian Produk Pakaian Bermerek Yang Dilakukan Staf Pengajar STIE Kesatuan Bogor. Jurnal IImiah Ranggagading (JIR), 12(1), pp.halaman-47

Rangkuti, Freddy. 2003. Teknik Mengukur dan Strategi Meningkatkan Kepuasan Pelanggan. Gramedia Pustaka Utama, Jakarta.

Ratminto dan Atik Septi Winarsih. 2005. Manajemen Pelayanan : Pengembangan Model Konseptual, Penerapan Citizen's Charter dan Standar Pelayanan Minimal. Pustaka Pelajar, Yogyakarta

Sekaran, Uma. 2006. Metodologi Penelitian untuk Bisnis. Jilid Pertama. Edisi Keempat. Penerjemah Kwan Men Yon. Salemba Empat, Jakarta.

Yazid. 1999. Pemasaran Jasa. Fakultas Ekonomi Ull., Yogyakarta. 